\title{
Thermo-Ecological Evaluation of a Nuclear Power Plant within the Whole Life Cycle
}

\author{
Wojciech Stanek ${ }^{* 1}$, Jan Szargut ${ }^{1}$, Zygmunt Kolenda ${ }^{2}$, \\ Lucyna Czarnowska ${ }^{1}$, Tomasz Bury ${ }^{1}$ \\ ${ }^{1}$ Silesian University of Technology, Institute of Thermal Technology, Gliwice, Poland \\ ${ }^{2}$ AGH - University of Science and Technology, Department of Fundamental Research in Energy Engineering, Kraków, \\ Poland E-mail: ${ }^{1}$ wojciech.stanek@ polsl.pl
}

Received 30 October 2014, Revised 11 March 2015, Accepted 14 March 2015

\begin{abstract}
Polish energy sector is mainly based on coal combustion, which is responsible for increasing the $\mathrm{CO} 2$ emission. Simultaneously, European trends toward sustainability and global warming mitigation will lead to significant changes in the structure of electricity generation in Poland. Due to the domestic energy policy the increase of renewable resources utilisation, as well as installation of first nuclear power units $\left(3 \times 1.6 \mathrm{GW}_{\mathrm{el}}\right)$, are planned in the perspective of the year 2030. The comparison of nuclear power plant with the existing coal ones requires the evaluation within the whole life cycle as well as the application of the common measure of the consumption of natural resources. Both requirements are fulfilled in the case of Thermo-Ecological Cost (TEC) analysis. TEC was introduced by Szargut and expresses the cumulative exergy consumption of non-renewable resources burdening the final consumed goods, e.g. electricity. Moreover, TEC takes into account the additional non-renewable exergy consumption required for mitigation of environmental losses caused by rejection of harmful waste products. In the paper, the TEC algorithm adopted for nuclear power plant is presented. In this case, the whole life cycle includes the following phases: 1) mining and milling, 2) conversion of fuel, 3) enrichment (diffusion or centrifuge), 4) fuel fabrication, 5) plant construction, 6) plant operations, 7) waste management, 8) plant decommissioning and 9) transport. The obtained results are compared with the average TEC index for the Polish energy mix. The direct exergy analysis shows that the direct exergetic efficiency of existing nuclear power unit is about $10 \%$ points lower than that of typical coal power unit. However, the TEC analysis proved that in the whole life cycle of the resource utilisation the exergetic efficiency is significantly lower in the case of the nuclear fuel cycle. The main cause of this imperfection appears in the stage of conversion, enrichment and nuclear fuel fabrication.
\end{abstract}

\section{Keywords: Exergy; thermo-ecological cost; life cycle; nuclear power plant.}

\section{Introduction}

As the majority of world production processes still rely on non-renewable natural resources and in the face of still growing consumption, the depletion of non-renewable natural resources of fossil fuels could be very dangerous for future activity or even existence of humankind. Especially, the power sector plays a significant role as the electricity is one of the most important energy carriers for many manufacturing processes. The continuous aspirations for further global economic growth additionally accelerate the consumption of finished stock of resources. It has to be stressed that the classic economy usually does not consider the constraints resulting from the limited accessibility of natural resources. For this reason, both methods to evaluate the resource efficiency and regulations for mitigating the uncontrollable increase of consumption seem to be of great importance. From the thermodynamic point of view, the imperfection of resources management can be investigated by means of exergy analysis. The concept of exergy cost [1] or cumulative exergy consumption [2-3] that are defined as the total amount of exergy needed to produce a unit of exergy of useful product, can be used to investigate the process of resources cost formation along the production chain. The cost increases through the chain of linked processes being dependent on the irreversibility of each component of that chain, not only on the final production stage. The cost, depending on the knowledge of component irreversibility, is the proper measure of the resource management efficiency.

In general, natural resources can be divided into renewable and non-renewable ones. Only in the last case, there is the danger of exhaustion and, only, this kind of resources should be taken into account in the case of ecological evaluation of production processes [4]. Advanced ecological application of exergy cost has been proposed by [5] as the Thermo-Ecological Cost (TEC). According to Szargut [5-7] the thermo-ecological cost is defined as cumulative consumption of non-renewable exergy connected with the fabrication of a particular product. The index of operational thermo-ecological cost can be determined by solving the set of thermo-ecological cost balances. The balance method of TEC calculation is described in Section 2 of the presented paper. The results of the TEC analysis may be used for the selection of production technology and for the optimization of the design and operational parameters of the production installations [8-10]. These results can lead to the minimisation of depletion of non-renewable resources that is one of the requirements of sustainable development. In the presented paper, the TEC method for evaluating the selected chain of nuclear power technology is applied. 


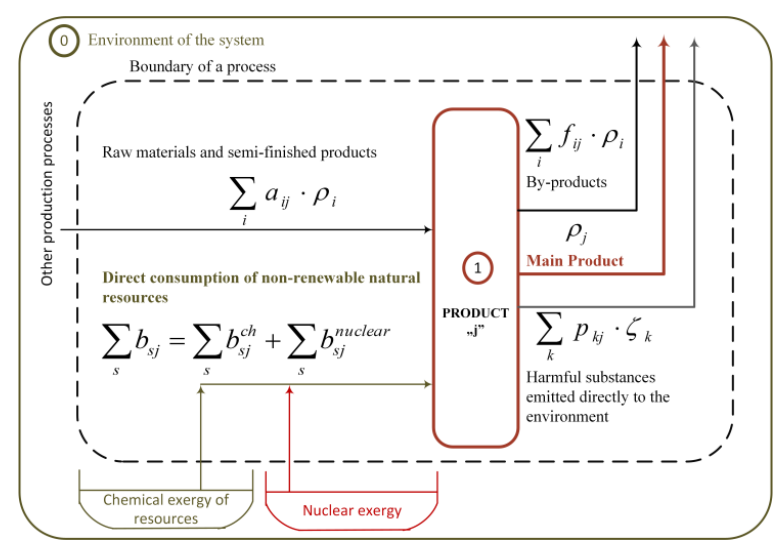

Figure 1. Idea of TEC balance equation.

It can be noticed, that from one hand the nuclear chain is often reported as lowest efficient [11]; however, from the other hand the reported accessible stock of resources of nuclear energy is much more abundant as that of fossil fuels. According to [11-12], the identified resources of uranium that could be extracted at the economic profitability amounts to 5.47 millions of tons which represent a total exergy of about $0.44 \cdot 1012$ TJ. The information about Resources (R), Production $(\mathrm{P})$ and Lifetime $(\mathrm{R} / \mathrm{P})$ of primary energy can be found e.g. in [1112]. The lifetime $(\mathrm{R} / \mathrm{P})$ in the case of fossil fuels is significantly limited [13]: natural gas -56 years, oil -53 years. In the case of coal during the last decade an extremely rapid decrease of $\mathrm{R} / \mathrm{P}$ index has been observed. The ratio R/P for coal in the year 2000 was estimated by [13] at the level of 220 years, after 12 years - in 2012 it is estimated as $\mathrm{R} / \mathrm{P}=109$ years. It means that through about 10 years the estimated lifetime of global coal resources decreased by 100 years. It is an evident symptom of the danger of exhaustion of non-renewable resources and it is the effect of the extensive influence of rapid development in some regions of the World which in turn also causes growing consumption. Unfortunately, consumption from the economical point of view is not constrained from the point of view of resources accessibility. In the face of this argument, it is probable that the power sector will have to use more nuclear resources. For the installed presently power at nuclear power plants, the lifetime of identified uranium resources is about 800 years. Besides the identified resources of uranium, there are also [12] not discovered, unconventional and ocean resources of nuclear energy. The total amount of nuclear resources could reach the level of $3 \cdot 1014 \mathrm{TJ}$, which consequently could ensure the enormous long R/P lifetime. The nuclear technology is an interesting option to conventional power plants, because of two facts:

- relatively short lifetime of conventional primary energy resources,

- relatively large amount of GHG emissions burdening fossil fuels combustion.

To estimate the efficiency of current management of uranium resources the TEC analysis of the whole nuclear cycle for two cases: average existing nuclear power plant open cycle and for average generation III+ power plant nuclear cycle is presented.

\section{Thermo-Ecological Cost (TEC) - Evaluation Method}

The physical cost of any product expressed by the TEC is mainly affected by the consumption of exergy of non- renewable resources extracted directly from the nature such as fuels, mineral ores, nuclear ores or fresh water [7-9]. This consumption appears in the production processes directly connected with the extraction of substances from the natural deposits, e.g. in the coal mine. Not all branches of economy are directly connected to the nature; however, due to interconnections in the production systems each product is linked to the natural resources. The TEC is also generated by consumption of semi-finished products $a_{i j}$ exchanged between branches of the system. In some branches, a by-production can appear. By-products replace main products in other branches and, therefore, the value of TEC of a considered main product is reduced. In the balance presented in Fig. 1 by-products are taken into account by the coefficient of by-production $f_{i j}$. TEC of the useful by-product should be determined by means of the avoided consumption of non-renewable exergy [8]. The balance of TEC of $j$-th production branch also includes an additional consumption of resources connected with the rejection of wastes to the environment $p_{k j}$. This additional consumption is connected with the maintenance and operation of abatement installations as well as from the necessity of compensation of other losses in the environment. The specific consumption $a_{i j}$ of $i$-th useful product in $j$-th branch is dependent on the exergetic efficiency of the production process. For this reason, the exergetic cost (TEC) is based purely on physical laws and its formation depends on the irreversibility of interconnected production processes. TEC ( $\rho$ in balance Eq. (1)) has been defined by Szargut [7]: the cumulative consumption of non-renewable exergy connected with the fabrication of a particular product with additional inclusion of the consumption resulting from the necessity of compensation of environmental losses caused by rejection of harmful substances to the environment. The index of operational TEC can be determined by solving the set of exergy cost balance equations. The equations are formulated using the scheme presented in Fig. 1.

According to the scheme of TEC balance presented in Fig. 1 the formula for calculation of the operational TEC [7-9] takes the following form:

$\rho_{j}+\sum_{i}\left(f_{i j}-a_{i j}\right) \rho_{i}=\sum_{s} b_{s j}^{c h}+\sum_{s} b_{s j}^{n u}+\sum_{k} p_{k j} \zeta_{k}$

The set of Eq. (1) should comprise all the branches of economy. However, it would be difficult to solve such problem. For this reason, in practical calculations only strongly connected production processes are taken into 
account [9]. The results of calculations of the thermoecological cost for many production technologies have been presented in details for example in [7-9, 14]; however, the present work contains the first application of TEC for evaluation of nuclear power chain.

The TEC of given primary non-renewable resources in the nature is equal to its specific exergy $(\mathrm{TEC})_{\text {prim }}=b_{s}[14]$. In the case of nuclear resources, the specific exergy $b_{s}$ in the TEC balance (Fig. 1) should, in general, include not only the chemical exergy of natural resource $b_{s j}^{c h}$ but also the nuclear exergy $b_{s j}^{n u}$. It should be checked, what is the influence of the chemical exergy and of the nuclear exergy of resources on the TEC calculation results using Eq. 1. The discussion of the importance of both parts of resource exergy on the TEC index is presented in Section 3.

As the TEC balance leads to the index expressed in one common measure - cumulative exergy of natural resources, the presented evaluation method represents an objective criterion based on fundamental physical law. In the TEC analysis, it is worth introducing additionally the Exergetic Sustainability Index (ExSI) that can be expressed as:

$$
(E x S I)_{j}=\frac{(T E C)_{j}}{b_{j}}
$$

Such an index expresses the ratio of thermo-ecological cost of the useful $j$-th product related to its specific exergy. The lower the index of sustainability, the better result is obtained from the ecological point of view, because we pay less cumulative exergy of natural resources per unit of exergy of particular useful products. The reverse of the $(E x S I)$ index expresses the system exergetic efficiency of non-renewable resources management. Aspirations for decreasing the sustainability index should be, of course, justifiable from the economic point of view.

The nuclear chain from uranium ore mine to end-use of electricity from a power plant is more complicated than the chain in the case of conventional power plants. For this reason, the TEC evaluation should also fulfil the requirements of Life Cycle Analysis [15]. The Thermo Ecological Life Cycle Assessment (TELCA) based on methodology, described in the previous section has to comprise the following phases:

1. Construction Phase encompasses the project, extraction of raw materials, fabrication of semi-finished products, transport expenditures in the construction phase. All these expenses influence the final thermo-ecological cost burdening the final useful product.

2. Operational phase is defined as a period between the end of the construction phase and a beginning of decommissioning phase. In processes utilising nonrenewable resources, this phase is predominant in the cumulative consumption of natural resources, mainly energy carriers.

3. Decommissioning phase of plant concerns the period at the end of installation's life. In this phase, thermoecological cost results from expenditures to develop the remains of the system and, for example, some expenditures for reclamation of terrain.

The general form of the equation to calculate the thermo-ecological cost in the whole life cycle has been formulated by Szargut and presented in [8]. This approach has been applied, for example, to investigate the exergetic life cycle of solar collector system in the work of [10]. This function, expressing the yearly thermo-ecological cost has the following form:

$$
\begin{aligned}
(T E C)_{L C A}=\tau_{n}\left(\sum_{i} \dot{G}_{i} \rho_{i}\right. & \left.+\sum_{k} \dot{P}_{k} \varsigma_{k}-\sum_{u} \dot{G}_{u} \varrho_{i} s_{i u}\right) \\
& +\frac{1}{\tau}\left(\sum_{m} G_{m} \rho_{m}\left(1-u_{m}\right)+\sum_{r} G_{r} \rho_{r}\right)
\end{aligned}
$$

To express the TEC by Eq. (1) with inclusion of the lifecycle per unit of useful product the Eq. (3) should be divided by the total yearly production of $j$-th main product $G_{P, j}$. Additionally the second part of the Eq. (3) should be divided by $\tau$ - nominal lifetime of the installation. In such approach, the specific consumption of construction material (index $I=$ investment part in the life-cycle) per unit of main product is introduced to the balance as:

$a_{i j}^{I}=\frac{G_{m}}{G_{P, j} \tau}$

After that the Eq. (3) (neglecting the influence of expenditures for repairs) takes the form similar to the Eq. (1):

$$
\begin{aligned}
\varrho_{j}^{L C A}+\sum_{i}\left[f_{i j}^{O}-a_{i j}^{O}-\right. & \left.a_{i j}^{I}\left(1-u_{i}\right)\right] \rho_{i}-\sum_{r} a_{r j} \rho_{r} \\
& =\sum_{s} b_{s j}^{c h}+\sum_{s} b_{s j}^{n u}+\sum_{k}\left(p_{k j}^{O}+p_{k j}^{I}\right) \zeta_{k}
\end{aligned}
$$

where: $)^{O}$ - operational phase, $)^{I}$ - investment phase.

Besides the information on the coefficient of specific consumption $a_{i j}$ of constructional materials and energy carriers for construction of each plant in the cycle the TEC indices $\rho_{i}$ for each raw material, semi-finished product or energy carrier consumed in the nuclear cycle has to be known. To determine these indices the EcoInvent v2.2 database has been applied [16]. For this reason, the introduced thermo-ecological cost of each product appearing in the cycle fulfils the requirement of LCA analysis. The results of calculations of thermo-ecological cost indices are included in the Table A.1 (Appendix A). The TEC of emissions are cited in Table A.2 (Appendix A).

\section{Chemical and Nuclear Exergy of Primary Natural Resources}

The chemical exergy of uranium ore has been calculated assuming that the minerals in the ore can be considered as an ideal solution of solid minerals. According to [8] the chemical exergy per mole of solution under normal thermodynamic parameters can be calculated from the following formula:

$$
(M b)_{\mathrm{ch}}=\sum_{i} z_{i}(M b)_{c h, i}+(M R) T_{0} \sum_{i} z_{i} \ln z_{i}
$$
ore)

Example 1 (calculation of chemical exergy of uranium

It has been assumed [17] that the exemplary uranium ore consists of $1940.0 \mathrm{~kg}$ of rock and $1.0 \mathrm{~kg}$ of uranium in the form of $\mathrm{U}_{3} \mathrm{O}_{8}$. The ore grade in the considered case is then $0.0515 \%$. The assumed data for estimation of chemical exergy by means of Eq. (6) is included in the Table B.1 (Appendix B). For the assumed uranium ore the final result of the chemical exergy is equal $b_{\text {ch,ore }}=0.14$ $\mathrm{MJ} / \mathrm{kg}$. 
The energy generated during single nuclear fission is proportional to the mass defect $\Delta m$ of the nuclear reaction. According to $[11,18], 5 \%$ of fission energy is associated with emitted neutrinos. The possibility of interaction of neutrinos and matter are practically zero. In other words the ability to perform work in this case is also zero. For this reason the nuclear exergy of fission has to be decreased by the fission energy associated with neutrinos. Additionally, it can be assumed that the change in entropy due to huge temperature and the change in concentration of products of nuclear fission in the relation to the environment both can be neglected. The values of fission energy and exergy (adopted from [11, 18]) for selected isotopes are presented in Table B.2 (Appendix B). Applying the values of fission exergy $b_{\text {fis }}$ included in Table B.2 (Appendix B) the exergy of nuclide per mass unit of the nuclide can be calculated from the formula:

$b_{\text {nuclide }}=\frac{N_{A}}{M_{\text {nu }}} b_{\text {fis }}$

When considering the nuclear carrier (primary - ore, or semi-finished - yellow cake, uranium hexafluoride or uranium fuel) to calculate the nuclear exergy the total fraction of the radioactive element $g_{r}$ and the fraction of fissile nuclide $g_{\text {fis }}$ in radioactive element have to be determined. For further consideration in this paper the fission of $\mathrm{U} 235$ is only taken into account, so $g_{r}=g_{\mathrm{U}}$ and $g_{\text {fis }}=g_{\mathrm{U} 235}$ and the nuclear exergy $b_{\text {nuclide }}=78.172 \cdot 10^{6}$ $\mathrm{MJ} / \mathrm{kg}$. The specific exergy of fissile nuclide carrier per its mass unit is calculated using the following formula:

$b_{\text {nu }}=g_{r} g_{\text {fis }} b_{\text {nuclide }}=g_{U} g_{\mathrm{U} 235} b_{\text {nuclide }}$

Example 2 (calculation of nuclear exergy of uranium ore)

Let assume the exemplary uranium ore with the ore grade 0.000515 of $\mathrm{kg} \mathrm{U}_{3} \mathrm{O}_{8} / \mathrm{kg}$ ore. It means that the uranium mass fraction in the ore is equal to $g_{U}=0.000437$ $\mathrm{kg} \mathrm{U} / \mathrm{kg}$ ore. According to [19-20], the mass fraction of $\mathrm{U} 235$ in natural uranium can be assumed at the level of $g_{\mathrm{U} 235}=0.007$. Applying the formula Eq. (8) the nuclear exergy of the considered uranium ore is calculated as:

$b_{\text {nu }}=g_{U} g_{\mathrm{U} 235} b_{\text {nuclide }}=0.000437 \cdot 0.007 \cdot 78.172 \cdot 10^{6}$ $=239.13 \mathrm{MJ} / \mathrm{kg}$ ore.

Comparing the results provided by calculation Example 1 and 2, it can be noticed, that the ratio of chemical exergy to nuclear exergy is equal to $b_{\mathrm{ch}} / b_{\mathrm{nu}}=0.0006$. For this reason, it can be assumed that in the calculation of thermoecological cost of nuclear energy carriers it is not necessary to include the chemical exergy of primary resources. The balance equation of TEC (Eqs. (1) or (5)) in the case of uranium ore mine should include only the direct nuclear exergy of primary resources. According to [20], uranium can also be mined from other useful minerals containing uranium. For example, in the Australian case uranium is extracted as a by-product of copper. According to data presented by [21] the chemical exergy of copper ore amounts to $0.63 \mathrm{MJ} / \mathrm{kg}$ ore, whereas in [9], it was calculated as $0.60 \mathrm{MJ} / \mathrm{kg}$. In this case the ratio of chemical to nuclear exergy is 0.0025 and the obtained results additionally confirm that the chemical exergy of ore can be neglected when the TEC balance is formulated for the process of uranium extraction. In further consideration in this work only nuclear exergy of primary uranium is taken into account in the TEC balances.

\section{Description of Full Cycle of the Considered LWR Reactor}

The thermo-ecological considerations with the inclusion of LCA are devoted in this paper to the open cycle with LWR - light water reactors (PWR or BWR). The detailed scheme of this cycle, which is presented in Fig. 2., considers the following stages:

1. Mining and milling of uranium ore (open pit and underground),

2. Conversion of $\mathrm{U}_{3} \mathrm{O}_{8}$ into $\mathrm{UF}_{6}$ for the enrichment process,

3. Enrichment of nuclear fuel (centrifuge and diffusion),

4. Fuel fabrication in the form of $\mathrm{UO}_{2}$,

5. Fuel transportation,

6. Power generation,

7. Depleted fuel management.

The data for the TEC calculation, which covers the whole life cycle of each step in the cycle of considered nuclear technology, are generally divided into two groups:

A. Data characterising the investment and decommissioning phase of the whole cycle. These data are used to calculate the coefficient of specific consumption $a_{i j}^{I}$ of constructional materials and energy carriers for construction of each plant in the cycle, which are necessary to solve the set of TEC balance Eq. (5). In this paper, only the example data for the stages: \#3A. - gas centrifuge enrichment and \#6. power generation are presented.

B. Data characterising the operational phase of each component in the cycle of considered nuclear technology. Additionally, the way of calculation of the uranium ore in the enrichment stage of the cycle as well as the way of calculation of specific fuel consumption in the power plant is presented. Coefficients of specific consumption or by-production in the operational phase are marked with upper symbol )$^{\mathrm{O}}-f_{i j}^{O}, a_{i j}^{O}$.

The source of the mentioned LCA inventory data was the report of NETL [17].

\section{Fuel enrichment (STAGE \#3)}

For the assumed degree of uranium enrichment $g_{F}$ and the assumed mass fraction in the depleted uranium $g_{T}$ the demand of the mass of natural uranium $m_{N}$ necessary to obtain $1 \mathrm{~kg}$ of the enriched uranium results from the mass balances of the separation cascade [11]:

$m_{N}=m_{F}+m_{T}$

$g_{N} m_{N}=g_{F} m_{F}+g_{T} m_{T}$

Combining (9) and (10) the index of specific consumption of natural uranium $(\mathrm{N})$ to produce enriched uranium $(\mathrm{F})$ can be calculated from the formula:

$a_{N, F}=\frac{g_{P}-g_{T}}{g_{N}-g_{T}}$

In the presented work it was assumed that the mass fraction of fissile U235 is as follows:

- in natural uranium $g_{N}=0.7 \%$,

- in enriched uranium $g_{F}=5.0 \%$,

in depleted uranium (by product of the enrichment process) $g_{T}=0.25 \%$. 


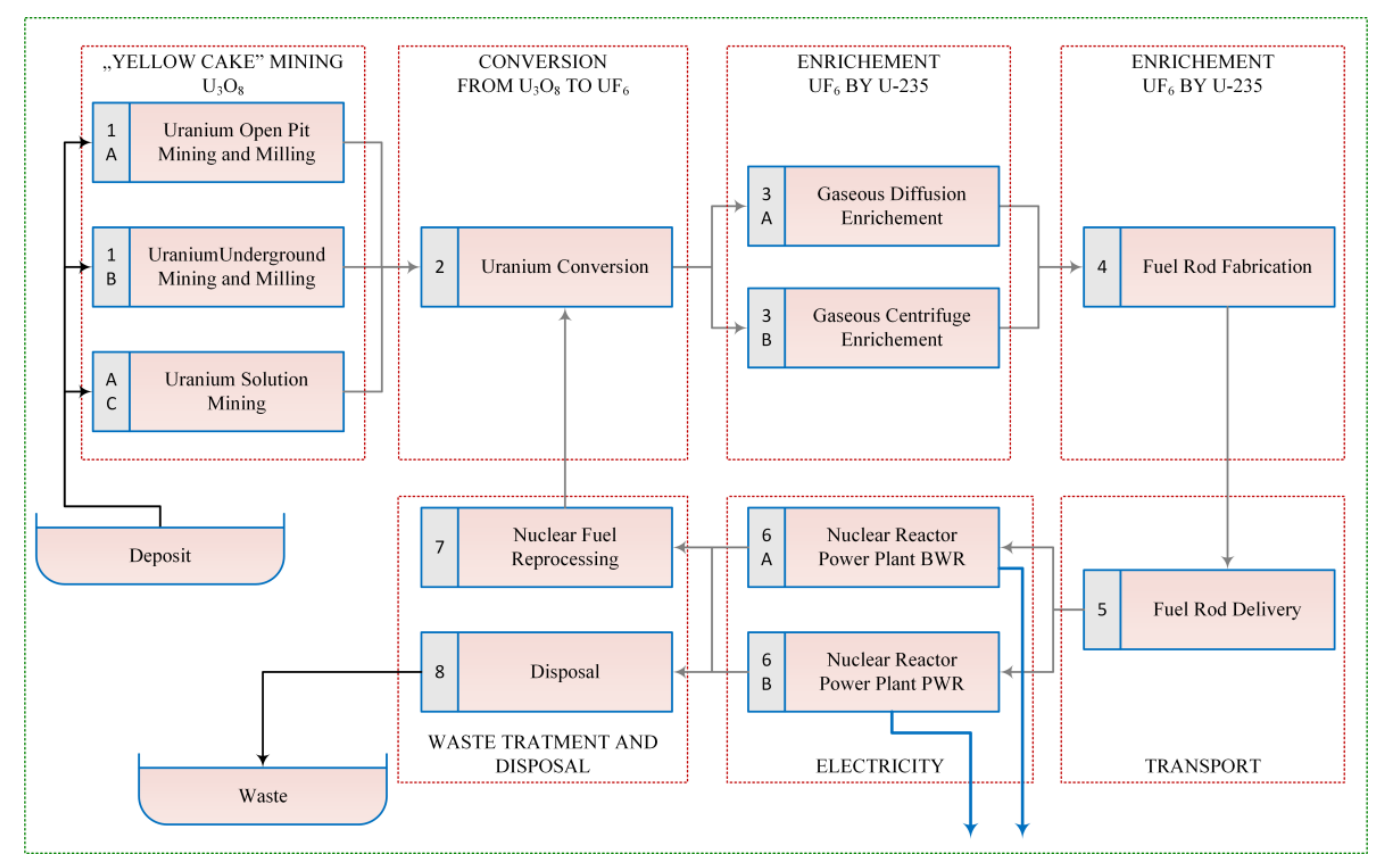

Figure 2. The whole cycle of nuclear technology.

From these assumptions and using the formula (Eq. 11) the requirement for natural uranium to produce $1 \mathrm{~kg}$ of enriched uranium $a_{N, F}=10.75 \mathrm{~kg} / \mathrm{kg}$ and the coefficient of by-production of depleted uranium is $f_{T F}^{O}=9.75 \mathrm{~kg} / \mathrm{kg}$. The other consumption- and by-production coefficients have been adopted from [15]. The input-output material balance of stage 3 (case - gas centrifuge enrichment) used in the TEC calculation procedure are included in Table C.1 (Appendix C).

\section{Power plant (Stage \#6)}

The nuclear plants are most often characterised by the energy efficiency of its thermodynamic cycle and the burnup ratio coefficient. The latter expressed usually in $\mathrm{GWd} / \mathrm{tU}$ is defined as:

$W_{F}=\frac{Q_{t h}}{m_{F}}$

Introducing into Eq. 12 the energy efficiency (thermal efficiency) of the nuclear plant defined as $\eta_{\mathrm{th}}=N_{\mathrm{el}} / Q_{t h}$ the specific consumption of fuel (tU) per electric energy production $(\mathrm{GWd})$ can be expressed as:

$a_{F, e l}^{O}=\frac{1}{\eta_{t h} W_{F}}$

The coefficient $a_{F, e l}^{O}$ is applied directly in TEC balance (Eq. 5) to calculate the thermo-ecological cost of electricity from power plant.

Example 3 (calculation of enriched nuclear fuel in power plant)

For the average existing reactor, it can be assumed that the burn-up rate is equal to $W_{F}=30.4 \mathrm{GWd} / \mathrm{tU}$. Thermal (energy) efficiency of this turbine cycle is equal to $\eta_{t h}=31.6 \%$. Knowing that $1 \mathrm{GWd}=86.4 \cdot 10^{6} \mathrm{MJ}$ the specific consumption of enriched uranium per unit of electricity is calculated by means of (Eq. 13):

$a_{F, e l}^{O}=1000.0 /\left(30.4 \cdot 86.4 \cdot 10^{6} \cdot 0.316\right)=1.204 \cdot 10^{-6}$

$\mathrm{kgUO}_{2} / \mathrm{MJ}_{\mathrm{el}}$. The calculated index of consumption is the basic factor that is introduced to the TEC balance (Eq. 5) and has the dominant influence on the exergetic efficiency of the nuclear power plant. Assuming for fuel $\mathrm{UO}_{2}$ $g_{\mathrm{U}}=0.8815$ and $g_{\mathrm{U} 235}=0.05$ and $b_{\text {nuclide }}=78.172 \cdot 10^{6} \mathrm{MJ} / \mathrm{kg}$ the nuclear exergy of fuel calculated from Eq. (8) is equal to $b_{\mathrm{nu}}=3445414.4 \mathrm{MJ} / \mathrm{kg} \mathrm{UO}$, and the exergetic efficiency of the power plant is equal to:

$\eta_{B, \mathrm{el}}=\frac{1}{a_{F, e l}^{O} b_{n u}}=24.1 \%$

The characteristics of the operational phase of considered nuclear power plants are included in Table 1. The results of calculation of local exergy efficiency of considered nuclear power plants. Two cases are presented $\eta_{\mathrm{B}, \mathrm{el}}-$ without reprocess of spent fuel and $\eta^{\prime}{ }_{\mathrm{B}, \mathrm{el}}-$ with reprocessing of spent fuel are also presented in Table 1.

Table 1. Basic Characteristic of Considered Nuclear Power Plants.

\begin{tabular}{|c|c|c|c|c|c|}
\hline No. & Parameter & Symbol & Unit & $\begin{array}{l}\text { Existing } \\
\text { Average* }\end{array}$ & $\begin{array}{l}\text { Gen. III+ PP } \\
\text { Average }\end{array}$ \\
\hline 1. & $\begin{array}{l}\text { Capacity } \\
\text { factor }\end{array}$ & $\beta$ & $\%$ & 70.7 & 93.4 \\
\hline 2. & $\begin{array}{l}\text { Thermal } \\
\text { efficiency }\end{array}$ & $\eta_{\text {th }}$ & $\%$ & 31.6 & 33.9 \\
\hline 3. & $\begin{array}{l}\text { Fuel } \\
\text { burn-up }\end{array}$ & $W_{F}$ & $\begin{array}{l}\mathrm{GW} \\
\mathrm{d} / \mathrm{tU}\end{array}$ & 30.4 & 49.6 \\
\hline 4. & $\begin{array}{l}\text { Fuel } \\
\text { consumpti } \\
\text { on }\end{array}$ & $a_{F, e l}^{O}$ & $\begin{array}{l}\mathrm{kg} / \\
\mathrm{MJ}\end{array}$ & $1.203 \mathrm{E}-06$ & $0.703 \mathrm{E}-06$ \\
\hline 5. & $\begin{array}{l}\text { Exergy } \\
\text { efficiency }\end{array}$ & $\underline{\eta_{B}, \mathrm{el}}$ & $\%$ & 24.1 & 41.3 \\
\hline
\end{tabular}

)* average value for existing in 2009 reactors 69 PWR $(66 \%)$ and 35 BWR (34\%) [17];

In the TEC calculations two cases of power generation are assumed and summarised in the Table 1 . Average existing technologies represent the average value from reactors 69 PWR (66\%) and 35 BWR (34\%) from the 2009 year [17]. The second case concerns the average values for 
the expected generation III+ nuclear power plant technologies. The exergy efficiency is mainly dependent on the internal exergy losses in the process of heat generation in the reactor. In the case of assumed parameters of existing PWR technology the exergy losses related to the nuclear exergy of fuel supplied to the reactor are as follows: reactor $\varepsilon_{R}=62,4 \%$, steam generator $\varepsilon_{\mathrm{SG}}=4,0 \%$ and turbine cycle $\varepsilon_{\mathrm{TC}}=9,4 \%$.

\section{Results of TEC Calculations and Discussion}

The calculation of TEC has been done for all the nuclear chain presented in Fig. 2 from uranium mine to the nuclear power plant. The indices of TEC of raw material, semifinished product or energy carrier supplied to the particular production process in the nuclear chain have been determined independently on the TEC balance set formulated for the nuclear chain. The results of these calculations are summarised in the Table A.1 (Appendix A). To calculate the TEC of products in the nuclear chain the separate set of TEC balances (Eq. 5) has been formulated. Each step has been characterised by the set of input-output data from LCA analysis. The exemplary set of input-output data, characterising the fuel enrichment, has been presented in the Table C.1 (Appendix C). In the calculations two cases of power plants has been considered: 1 - average existing plant, 2 - average future plant in GEN III+ technology. The assumed characteristics of the considered nuclear power plants are included in the Table 1. However, in Table 2 the results of the TEC analysis of the nuclear chain between from uranium coal mine (cradle) throughout fuel fabrication and transportation are summarised. Table 2 presents the total TEC characterising each step in the chain, exergy of the product of each stage of the nuclear chain $b_{P}$, specific TEC of the products $\rho_{P}$ of each step that represent the exergetic cost of non-renewable resources. Additionally, in Table 2 the local exergetic efficiency of each stage of the production chain $\eta_{B}$ and system (cumulative) exergy efficiency $\eta_{B}^{*}$ characterising the exergetic cost formation after each step of the production chain is presented. It is evident that due to relatively huge nuclear exergy of the chain products the external TEC burdening the process of mining and transportation is negligible because of relatively low TEC of the external products. The process of conversion and fuel fabrication are characterised by the highest exergy losses and mainly influencing the formation of the exergetic cost of all the production chain. These processes are characterised by the following local exergy efficiencies: conversion $-28.35 \%$ and fuel fabrication $-38.12 \%$. Also the process of fuel enrichment is resource consuming as its local exergy efficiency amounts to: centrifuge enrichment $-66.43 \%$ and diffusion enrichment $67.99 \%$. It should be stressed that in the process of exergetic cost formation the transformations of nuclear carriers and its nuclear exergy plays the dominant role. The share of nuclear exergy in the total TEC in the following stages: mining, conversion and enrichment is over $98 \%$. It means that the consumption of other materials and energy carriers in the life cycle TEC calculation plays a marginal role.

Using the indices of TEC for the whole nuclear cycle the TEC of electricity generated in nuclear power plant has been determined. Two cases have been examined: average existing nuclear power plant (69 PWR $(66 \%)$ and 35 BWR $(34 \%))$ and average nuclear power plant of generation III+. The results of the calculations are compared in the Table 3.

Table 3. Results of TEC Analysis of Nuclear Power Plant.

\begin{tabular}{lrrr}
\hline Power plant & $\begin{array}{l}\text { Local } \\
\text { exergy } \\
\text { efficiency } \\
\eta_{\mathrm{B}, \mathrm{el}}, \%\end{array}$ & $\begin{array}{l}\text { (TEC) }_{\mathrm{LCA}} \\
\text { MJ*/MJ }\end{array}$ & $\begin{array}{l}\text { System } \\
\text { exergy } \\
\text { efficiency } \\
\eta^{*} \text { B,el, \% }\end{array}$ \\
\hline 1. Nuclear existing & 24.1 & 58.39 & 1.71 \\
2. Nuclear Gen III + & 41.3 & 34.13 & 2.93 \\
$\begin{array}{l}\text { 3. Nuclear existing } \\
\text { (recycling) }\end{array}$ & 27.0 & 57.80 & 1.73 \\
$\begin{array}{l}\text { 4. Nuclear GEN III + } \\
\text { (recycling) }\end{array}$ & 46.2 & 33.78 & 2.96 \\
$\begin{array}{l}\text { 5. Coal average in } \\
\text { Poland }\end{array}$ & 31.8 & 3.90 & 25.64 \\
\hline
\end{tabular}

Figure 3 presents a graphical comparison of exergy efficiency of power plants included in Table 3. System exergy efficiency has been determined as the reverse of TEC.

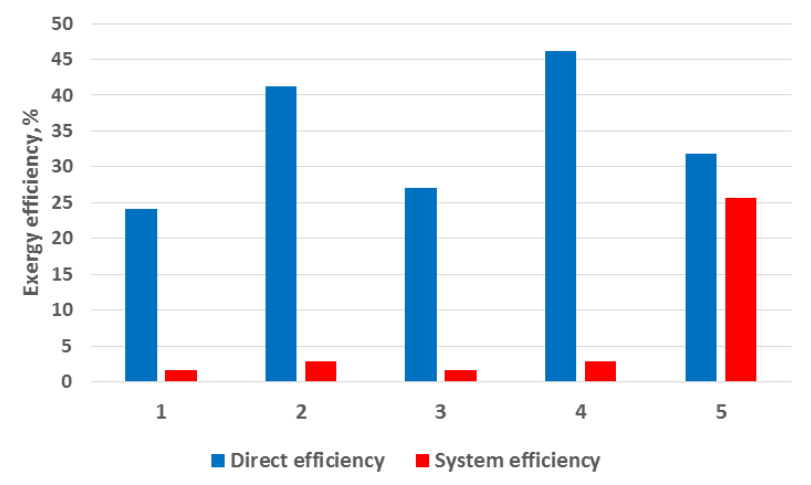

Figure 3. Comparison of exergy efficiency.

It can be observed, that in the case of the existing power plant the local exergy efficiency is lower of about $8 \%$ points than that in the case of average coal power plant in Poland. The recycling of spent fuel increases the local exergy efficiency of about three percent point. Nuclear power plant of generation III+ can achieve the local exergy efficiency of about $41.3 \%$, which is higher than in the case of the existing coal power plant of about 10 percent point of. The recycling can further improve the efficiency reaching the level of $46.2 \%$. However, due to the extremely high exergy losses in the nuclear chain from mine to the fuel fabrication process, the system exergy efficiency of the whole nuclear power plant cycle is very low. In the case of the existing technology, it is about $1.7 \%$, in the considered generation III+ about $2.9 \%$. It is about 10 times lower than the system exergy efficiency of the existing coal power plant that amounts to $25.6 \%$. Processes of fuel conversion and enrichment have the dominant influence on the high exergetic cost of the whole nuclear chain. 
Table 2. Results of TEC Analysis of Fuel Chain Uranium Mine - Power Plant.

\begin{tabular}{llrrrrr}
\hline Stage & Product & $\begin{array}{r}\text { Total } \\
(\mathrm{TEC}), \\
\mathrm{GJ} / \mathrm{kg}\end{array}$ & $\begin{array}{r}\text { Exergy of } \\
\text { product } b_{P} \\
\mathrm{GJ} / \mathrm{kg}\end{array}$ & $\begin{array}{r}\text { Specific TEC } \\
\rho_{P}\end{array}$ & $\begin{array}{r}\text { Stage exergy } \\
\text { efficiency } \\
\eta_{B}, \%\end{array}$ & $\begin{array}{r}\text { System exergy } \\
\text { efficiency } \\
\eta_{B}^{*}, \%\end{array}$ \\
\hline $\begin{array}{l}\text { Mining (open pit } \\
\text { mine) }\end{array}$ & $\begin{array}{l}\mathrm{U}_{3} \mathrm{O}_{8}, \\
\text { yellowcake }\end{array}$ & 466.68 & 464.03 & 1.006 & 99.43 & 99,43 \\
$\begin{array}{l}\text { Mining } \\
\text { (underground) }\end{array}$ & $\begin{array}{l}\mathrm{U}_{3} \mathrm{O}_{8}, \\
\text { yellowcake }\end{array}$ & 471.98 & 464.03 & 1.017 & 98.31 & 98.31 \\
$\begin{array}{l}\text { Conversion } \\
\text { Enrichment } \\
\text { (centrifuge) }\end{array}$ & $\mathrm{UF}_{6}(0.7 \%)$ & 1320.05 & 370.01 & 3.568 & 28.35 & 28.03 \\
$\begin{array}{l}\text { Enrichment(diffusi } \\
\text { on) }\end{array}$ & $\mathrm{UF}_{6}(5.0 \%)$ & 14193.83 & 2642.91 & 5.370 & 66.43 & 18.62 \\
$\begin{array}{l}\text { Fuel fabrication } \\
\text { Transport }\end{array}$ & $\mathrm{UF}_{6}(5.0 \%)$ & 13867.14 & 2642.91 & 5.247 & 67.99 & 19.06 \\
\hline
\end{tabular}

\section{Summary and Final Conclusions}

In the article, the proposal of application of thermoecological cost (TEC) for the evaluation of full nuclear cycle is presented. The influence of the examined technology on the depletion of non-renewable resources is proposed as the evaluation criterion of TEC. Moreover, the TEC indices of all stages from the uranium mine to the power plant including data from LCA for this chain are calculated.

The results show that the direct exergy efficiency of the nuclear power plant is at the competitive level in comparison with the conventional coal power plant. However, in the case of the full cycle from uranium mine to power plant gate, the enormous exergy losses in comparison with coal chain occur. This is the reason of relatively high TEC of the whole chain of nuclear fuel fabrication. These processes are characterised by the following local exergy efficiencies: conversion $-28.35 \%$ and fuel fabrication $-38.12 \%$. Also the process of fuel enrichment is resource consuming, as its local exergy efficiency amounts to: centrifuge enrichment $-66.43 \%$ and diffusion enrichment $67.99 \%$.

It should be also stressed that in the process of exergetic cost formation the transformations of nuclear carriers and its nuclear exergy plays the dominant role. The share of nuclear exergy in the total TEC in mining, conversion and enrichment stage is over $98 \%$. Due to the extremely high exergy losses in the nuclear chain from mine to the fuel fabrication process and fuel transport into reactor that influence the rapid increase in the exergetic cost formation, the system exergy efficiency of the whole nuclear power plant cycle is very low. In the case of the existing technology, the exergy efficiency is about $1.7 \%$, whereas, in the considered generation III+ is equal about $2.9 \%$. The TEC considerations shown clearly that the evaluation of nuclear power plant by means of direct indices (direct energy efficiency or direct exergy efficiency) is insufficient or even can be misleading. Due to the losses appearing in the preliminary stages of production chain it is necessary to evaluate this technology using system exergy analysis and taking into account the sustainability of non-renewable resources - using the thermo-ecological cost methodology with inclusion of the whole life cycle.

It should be additionally stressed that the presented approach is the first application of the cumulative exergy assessment by means of TEC of full nuclear chain. Additionally, the results of calculations are strongly dependent on the indices of specific consumption characterising all the life cycle stages in nuclear chain. The data and literature devoted to the investigated problem is not sufficient, for this reason the authors are going to continue the investigations in order to improve the reliability of the LCA data for the exergetic TEC algorithms. Additionally, the further analysis should present the multi-criteria evaluation by mans of economic and cumulative greenhouse gasses emission. This is caused by the fact that the unit cost of electricity from nuclear power plant is significantly lower than from conventional technologies, and nuclear chain is less responsible for $\mathrm{CO}_{2}$ emissions. Additionally, it has to be pointed out that even the TEC of electricity from nuclear power plant is enormous high the advantage of this technology lies in the significantly longer lifetime $(\mathrm{R} / \mathrm{P})$ of uranium resources in comparison with the resources of conventional fuels.

\section{Acknowledgements:}

This work has been developed thanks to the support from the statutory research fund of the Faculty of Power and Environmental Engineering of Silesian University of Technology.

This work was supported by the National Centre for Research and Development (Project HTRPL, Contract No. $\mathrm{SP} / \mathrm{J} / 1 / 166183 / 12$ ) and partially by Polish Ministry of Science and Higher Education, Grant AGH, No.11.11.210.198.

\section{Nomenclature}

$a_{i j} \quad$ coefficient of the consumption of the i-th product per unit of the $\mathrm{j}$-th major product,

$b_{f i s} \quad$ specific fission exergy,

$b_{c h} \quad$ specific chemical exergy,

$b_{\text {nuclide }}$ specific exergy of nuclide per mass unit,

$b_{s} \quad$ specific exergy of primary natural resource,

$b_{s j}^{c h} \quad$ chemical exergy of the s-th non-renewable natural resource immediately consumed in the process under consideration per unit of the $\mathrm{j}$-th product,

$b_{s j}^{n u} \quad$ nuclear exergy of the s-th non-renewable natural resource immediately consumed in the process under consideration per unit of the $\mathrm{j}$-th product,

ExSI exergetic sustainability indicator,

$f_{i j} \quad$ coefficient of the consumption and by production of the $\mathrm{i}$-th product per unit of the $\mathrm{j}$-th major product,

$g_{i} \quad$ mass fraction of $\mathrm{i}-$ th component of solution, 
$\dot{G}_{i} \quad$ nominal flow rate of the i-th raw material, semifinished product or energy carrier supplied to the production process,

$\dot{G}_{u}$ nominal production rate of the useful u-th by product,

$G_{m} \quad$ consumption of the m-th energy carrier used for the construction of the installation,

$G_{P, j} \quad$ total yearly production of j-th main product,

$G_{r} \quad$ expected consumption of the $r$-th material or energy carrier used in repairs,

$m_{F} \quad$ mass of the enriched fuel,

$m_{N} \quad$ mass of natural fuel,

$m_{T}$ mass tail uranium fuel,

$M b_{c h, i}$ molar chemical exergy of $i$-th component of solution,

$M_{n u} \quad$ molar mass of nuclide, $\mathrm{kg} / \mathrm{kmol}$,

$M R$ universal gas constant,

$N_{A} \quad$ Avogadro number $\left(6.02214129 \cdot 10^{26} 1 / \mathrm{kmol}\right)$,

$p_{k j} \quad$ total amount of $k$-th waste product generated in $j$-th production branch,

$\dot{P}_{k} \quad$ nominal flow rate of the $k$-th deleterious waste product rejected to the environment,

$Q_{t h} \quad$ amount of heat generated during reactor campaign,

$s_{i u}$ replacement ratio in units of the $i$-th replaced product per unit of the $u$-th by-product,

$T_{0} \quad$ absolute ambient temperature,

$u_{m} \quad$ expected recovery factor of the $m$-th material,

$W_{F}$ burn-up ratio coefficient, $\mathrm{GWd} / \mathrm{t}$,

$z_{i} \quad$ molar fraction of $i$-th component of solution.

\section{Greek symbols}

$\zeta_{k} \quad$ total thermo-ecological compensation cost of loses in the environment caused by the rejection of $\mathrm{k}$-th contaminant,

$\eta_{t h} \quad$ thermal efficiency of the turbine cycle,

$\rho_{i}, \rho_{j}$ thermo-ecological cost (TEC) of the $i$-th and $j$-th main product,

$\rho_{m}, \rho_{r}$ thermo-ecological cost of the $m$-th material or energy carrier used in construction phase and thermo-ecological cost of the $r$-th useful good used in installations repairs,

$\varsigma_{k} \quad$ index of specific thermo-ecological cost of the $k$-th deleterious waste product rejected to the environment,

$\tau_{n} \quad$ annual operation time with nominal capacity,

$\varrho_{i} \quad$ specific thermo-ecological cost of the $i$-th major product,

$\tau \quad$ nominal lifetime of the installation.

\section{Superscripts}

)$^{O} \quad$ operational phase,

)$^{I} \quad$ investment phase.

\section{References:}

[1] Lozano, M.A. and Valero, A. (1993). Theory of the Exergetic Cost. Energy,( 18) 9, pp. 939-960.

[2] Szargut, J. and Morris D.R. (1987). Cumulative exergy consumption and cumulative degree of perfection of chemical processes. Energy Research, 11, pp. 245-261.

[3] Szargut, J. (1987). Analysis of cumulative exergy consumption. Energy Research 4, pp. 541-547.
[4] Szargut, J. (1978). Minimization of the consumption of natural resources. Bull. Pol. Acad. Sci., Techn., 6, pp. 41-45.

[5] Szargut, J. (1986). Application of exergy for the calculation of ecological cost. Bull. Pol. Acad. Sci., Techn., 7-8, pp. 475-480.

[6] Szargut, J. (1997). Depletion of unrestorable natural exergy resources. Bull. Pol. Acad. Sci., Techn., 2, pp. 241-250.

[7] Szargut, J., et. al. (2002). Depletion of the nonrenewable natural exergy resources as a measure of the ecological cost. Energy Conversion \& Management. 42, pp. 1149-1163.

[8] Szargut, J. (2005). Exergy Analysis: Technical and Ecological Applications. WIT-press, Southampton.

[9] Stanek, W.(2009). Method of evaluation of ecological effects in thermal processes with the application of exergy analysis. Silesian University of Technology Press, 2009 (in Polish).

[10] Szargut, J. and Stanek W. (2007). Thermo-ecological optimization of a solar collector. Energy 32, 584-590.

[11] Tani, F., et. al. (2010). Exergy-based Comparison of the Nuclear Fuel Cycles of Light Water and Generation IV Reactors. Proc. Conf. ECOS 2010. Lausanne, Switzerland.

[12] Hermann, W. (2006)., Quantifying global exergy resources, Energy, 31(12), pp. 1685- 1702.

[13] Statistical Review of World Energy 2013. www.bp.com, last accessed 23.01.2014.

[14] Szargut, J. and Stanek W. (2012). Fuel Part and Mineral Part of the Thermoecological Cost. International Journal of Thermodynamics. 15(4), pp. 187-190. DOI: 10.5541/ijot.419.

[15] Stanek, W. (2012). Examples of Application of Exegy Analysis for the Evaluation of Ecological Effects in Thermal Processes. International Journal of Thermodynamics, 15( 1).

[16] Ecoinvent reports http://www.ecoinvent.ch/

[17] Role of Alternative Energy Sources: Nuclear Technology Assessment. DOE/NETL-2011/1502. August 8, 2012. National Energy Technology Laboratory. www.netl.doe.gov, last accessed 23.01.2014.

[18] Duderstadt, J.J. and Hamilton, L.J. (1976). Nuclear Reactor Analysis, John Wiley \& Sons, New York.

[19] Celinski, Z. and Strupczewski, A. (1984). Nuclear Power. WNT Warszawa (in Polish).

[20] Lenzen, M. (2008). Life cycle energy and greenhouse gas emissions of nuclear energy: A review. Energy Conversion and Management 49, pp. 2178-2199.

[21] Finneveden, G. and Ostlund, P. (1997). Exergies of natural resources in life-cycle assessment and other applications. Energy, 22(9). 
Appendix A - Indices of Thermo-Ecological Cost of materials in the whole nuclear life cycle

Table A.1 Thermo-ecological Cost of Products Consumed in the Whole Nuclear Cycle.

\begin{tabular}{|c|c|c|c|}
\hline No. & Product & Unit & TEC \\
\hline 1. & Aluminium & $\mathrm{MJ}_{\mathrm{ex}} / \mathrm{kg}$ & 185.16 \\
\hline 2. & Aluminium sheet & $\mathrm{MJ}_{\mathrm{ex}} / \mathrm{kg}$ & 194.53 \\
\hline 3. & Ammonia & $\mathrm{MJ}_{\mathrm{ex}} / \mathrm{kg}$ & 41.52 \\
\hline 4. & Ammonium nitrate & $\mathrm{MJ}_{\mathrm{ex}} / \mathrm{kg}$ & 61.98 \\
\hline 5. & Bitumen & $\mathrm{MJ}_{\mathrm{ex}} / \mathrm{kg}$ & 52.23 \\
\hline 7. & Cast iron & $\mathrm{MJ}_{\mathrm{ex}} / \mathrm{kg}$ & 36.14 \\
\hline 8. & Chlorine & $\mathrm{MJ}_{\mathrm{ex}} / \mathrm{kg}$ & 93.43 \\
\hline 9. & Concrete, ready mix. R-5-0 & $\mathrm{MJ}_{\mathrm{ex}} / \mathrm{kg}$ & 1.60 \\
\hline 10. & Copper & $\mathrm{MJ}_{\mathrm{ex}} / \mathrm{kg}$ & 145.00 \\
\hline 11. & Copper sheet & $\mathrm{MJ}_{\mathrm{ex}} / \mathrm{kg}$ & 145.00 \\
\hline 12. & Diesel & $\mathrm{MJ}_{\mathrm{ex}} / \mathrm{kg}$ & 53.53 \\
\hline 13. & Electricity and power & $\mathrm{MJ}_{\mathrm{ex}} / \mathrm{MJ}$ & 4.78 \\
\hline 14. & Hydrated lime dry slaked & $\mathrm{MJ}_{\mathrm{ex}} / \mathrm{kg}$ & 4.10 \\
\hline 15. & Hydrogen peroxide & $\mathrm{MJ}_{\mathrm{ex}} / \mathrm{kg}$ & 20.92 \\
\hline 16. & Ion exchange resin & $\mathrm{MJ}_{\mathrm{ex}} / \mathrm{kg}$ & 0.86 \\
\hline 17. & Lead & $\mathrm{MJ}_{\mathrm{ex}} / \mathrm{kg}$ & 101.00 \\
\hline 18. & Light fuel oil & $\mathrm{MJ}_{\mathrm{ex}} / \mathrm{kg}$ & 52.89 \\
\hline 19. & Locomotive transport & $\mathrm{MJ}_{\mathrm{ex}} / \mathrm{tkm}$ & 0.62 \\
\hline 20. & Manganese ore & $\mathrm{MJ}_{\mathrm{ex}} / \mathrm{kg}$ & 0.75 \\
\hline 21. & Natural gas & $\mathrm{MJ}_{\mathrm{ex}} / \mathrm{kg}$ & 48.80 \\
\hline 22. & Nickel $99.95 \%$ & $\mathrm{MJ}_{\mathrm{ex}} / \mathrm{kg}$ & 238.25 \\
\hline 23. & Oxygen & $\mathrm{MJ}_{\mathrm{ex}} / \mathrm{kg}$ & 5.91 \\
\hline 24. & Polyurethane flexible foam (PU) & $\mathrm{MJ}_{\mathrm{ex}} / \mathrm{kg}$ & 90.13 \\
\hline 25. & Polyvinyl chloride-tube & $\mathrm{MJ}_{\mathrm{ex}} / \mathrm{kg}$ & 47.85 \\
\hline 26. & Silver & $\mathrm{MJ}_{\mathrm{ex}} / \mathrm{kg}$ & 1555.86 \\
\hline 27. & Sodium carbonate & $\mathrm{MJ}_{\mathrm{ex}} / \mathrm{kg}$ & 18.44 \\
\hline 28. & Sodium chlorate & $\mathrm{MJ}_{\mathrm{ex}} / \mathrm{kg}$ & 46.59 \\
\hline 29. & Sodium chloride & $\mathrm{MJ}_{\mathrm{ex}} / \mathrm{kg}$ & 3.10 \\
\hline 30. & Stainless steel cold rolled & $\mathrm{MJ}_{\mathrm{ex}} / \mathrm{kg}$ & 86.54 \\
\hline 31. & Steel products, pipe welded, BF & $\mathrm{MJ}_{\mathrm{ex}} / \mathrm{kg}$ & 35.70 \\
\hline 32. & Sulphuric acid (100\%) & $\mathrm{MJ}_{\mathrm{ex}} / \mathrm{kg}$ & 14.53 \\
\hline 33. & Energy from diesel & $\mathrm{MJ}_{\mathrm{ex}} / \mathrm{MJ}$ & 1.30 \\
\hline 34. & Energy from natural gas & $\mathrm{MJ}_{\mathrm{ex}} / \mathrm{MJ}$ & 1.18 \\
\hline 35. & Timber pine & $\mathrm{MJ}_{\mathrm{ex}} / \mathrm{kg}$ & 0.25 \\
\hline 36. & Water & $\mathrm{MJ}_{\mathrm{ex}} / \mathrm{kg}$ & 0.03 \\
\hline
\end{tabular}

Table A.2 Thermo-ecological Cost of Waste Products Rejected in the Whole Nuclear Cycle.

\begin{tabular}{lllr}
\hline No & Waste & Unit & \multicolumn{1}{c}{$\zeta_{k}$} \\
\hline 1. & $\mathrm{CO}_{2}$ & $\mathrm{MJ} / \mathrm{kg}$ & 4.4 \\
2. & $\mathrm{SO}_{\mathrm{x}}$ & $\mathrm{MJ} / \mathrm{kg}$ & 97.82 \\
3. & $\mathrm{NO}_{\mathrm{x}}$ & $\mathrm{MJ} / \mathrm{kg}$ & 71.88 \\
4. & $\mathrm{PM}$ & $\mathrm{MJ} / \mathrm{kg}$ & 53.42 \\
6. & Methane & $\mathrm{MJ} / \mathrm{kg}$ & 123.2 \\
\hline
\end{tabular}


Appendix B - Uranium ore composition and fission exergy

Table B.1. Data Used for Chemical Exergy Calculation of Uranium Ore.

\begin{tabular}{lll}
\hline Ore component & $\begin{array}{l}\text { Mole fraction } \\
\mathrm{kmol} / \mathrm{kmol}\end{array}$ & $\begin{array}{l}\text { Normal chemical exergy } \\
\mathrm{kJ} / \mathrm{kmol}\end{array}$ \\
\hline U3O8 & 0.00161 & 236200.0 \\
Albite & 0.49679 & 21900.0 \\
Quartz & 0.05580 & 2200.0 \\
Anortite & 0.04862 & 66000.0 \\
Phlogopite & 0.15574 & 175246.5 \\
Tremolite & 0.24143 & 79700.0 \\
\hline
\end{tabular}

Table B.2. Energy and Exergy of Fission and of Nuclide.

\begin{tabular}{llll}
\hline Nuclide & $\begin{array}{l}\text { Fission energy, } e_{\text {fis }} \\
\text { MeV }\end{array}$ & $\begin{array}{l}\text { Fission exergy, } b_{\text {fis }} \\
\text { MeV }\end{array}$ & $\begin{array}{l}\text { Exergy of nuclide, } b_{\text {nuclide }} \\
\mathrm{MJ} / \mathrm{kg}\end{array}$ \\
\hline $\mathrm{U} 233$ & 200.0 & 190.0 & $77.016 \cdot 10^{6}$ \\
$\mathrm{U} 235$ & 203.0 & 192.9 & $78.172 \cdot 10^{6}$ \\
$\mathrm{U} 238$ & 208.9 & 198.5 & $80.444 \cdot 10^{6}$ \\
Th232 & 200.0 & 190.0 & $79.018 \cdot 10^{6}$ \\
Pu239 & 208.9 & 198.5 & $78.475 \cdot 10^{6}$ \\
Pu241 & 210.8 & 200.3 & $79.189 \cdot 10^{6}$ \\
\hline
\end{tabular}


Appendix C - TEC balance - example of input data

Table C.1. Example Set of Data to Solve the TEC Balance.

\begin{tabular}{|c|c|c|c|}
\hline & Flow name & Value & Unit \\
\hline \multirow{15}{*}{ 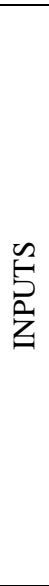 } & \multicolumn{3}{|c|}{$a_{i j}^{I}=$ inputs during the construction of installation, } \\
\hline & Bitumen & $7.21 \mathrm{E}+00$ & $\mathrm{~kg} / \mathrm{kg}$ UF6 \\
\hline & Concrete & $1.41 \mathrm{E}+01$ & $\mathrm{~kg} / \mathrm{kg}$ UF6 \\
\hline & Copper & $1.71 \mathrm{E}-02$ & $\mathrm{~kg} / \mathrm{kg}$ UF6 \\
\hline & Aluminium sheet & $2.90 \mathrm{E}-01$ & $\mathrm{~kg} / \mathrm{kg} \mathrm{UF6}$ \\
\hline & Steel pipe welded & $1.56 \mathrm{E}-04$ & $\mathrm{~kg} / \mathrm{kg}$ UF6 \\
\hline & Steel plate & $5.09 \mathrm{E}-05$ & $\mathrm{~kg} / \mathrm{kg} \mathrm{UF6}$ \\
\hline & Water & $7.49 \mathrm{E}-01$ & $\mathrm{~kg} / \mathrm{kg} \mathrm{UF6}$ \\
\hline & Diesel & $1.32 \mathrm{E}+00$ & $\mathrm{~kg} / \mathrm{kg} \mathrm{UF6}$ \\
\hline & \multicolumn{3}{|c|}{$a_{i j}^{O}=$ inputs during the operation of an installation, } \\
\hline & Natural UF6 (0.7\%) & 10.7500 & $\mathrm{~kg} / \mathrm{kg}$ UF6 \\
\hline & Power & 540 & $\mathrm{MJ} / \mathrm{kg} \mathrm{UF6}$ \\
\hline & Natural gas & 148.5700 & MJ/kg UF6 \\
\hline & Diesel & 0.251 & $\mathrm{~kg} / \mathrm{kg} \mathrm{UF6}$ \\
\hline & Water & 1100.0000 & $\mathrm{~kg} / \mathrm{kg}$ UF6 \\
\hline \multirow{16}{*}{ 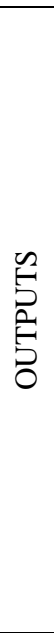 } & \multicolumn{3}{|c|}{$p_{k j}^{I}=$ outputs - emissions burdening during the construction of an installation, } \\
\hline & $\mathrm{CO} 2$ & 4.1 & $\mathrm{~kg} / \mathrm{kg}$ UF6 \\
\hline & NOx & 4.12E-02 & $\mathrm{kg} / \mathrm{kg}$ UF6 \\
\hline & SOx & $5.34 \mathrm{E}-03$ & $\mathrm{~kg} / \mathrm{kg} \mathrm{UF6}$ \\
\hline & $\mathrm{CO}$ & $2.63 \mathrm{E}-02$ & $\mathrm{~kg} / \mathrm{kg} \mathrm{UF} 6$ \\
\hline & Dust (PM10) & $2.08 \mathrm{E}-02$ & $\mathrm{~kg} / \mathrm{kg}$ UF6 \\
\hline & \multicolumn{3}{|c|}{$f_{i j}^{O}=$ outputs during the operation of an installation, } \\
\hline & Depleted UF6 $(0,25 \%)$ & 9.75 & $\mathrm{~kg} / \mathrm{kg}$ UF6 \\
\hline & Water & 36.3 & $\mathrm{~kg} / \mathrm{kg}$ UF6 \\
\hline & Waste solid for disposal & 21.6 & $\mathrm{~kg} / \mathrm{kg}$ UF6 \\
\hline & \multicolumn{3}{|c|}{$p_{k j}^{O}=$ outputs - emissions burdening during the operation of an installation, } \\
\hline & $\mathrm{CO} 2$ & 7.91E-01 & kg / kg UF6 \\
\hline & NOx & $6.48 \mathrm{E}-03$ & $\mathrm{~kg} / \mathrm{kg} \mathrm{UF6}$ \\
\hline & SOx & $7.45 \mathrm{E}-06$ & $\mathrm{~kg} / \mathrm{kg}$ UF6 \\
\hline & Methane & $3.24 \mathrm{E}-02$ & $\mathrm{~kg} / \mathrm{kg}$ UF6 \\
\hline & Dust (PM10) & $1.25 \mathrm{E}-04$ & $\mathrm{~kg} / \mathrm{kg}$ UF6 \\
\hline
\end{tabular}

